\title{
Doğu Akdeniz Bölgesi Ballarının Pestisit ve Naftalin Kalıntılarının LC/MS/MS ve HS-SPME GC/MS Teknikleriyle Belirlenmesi
}

\author{
Cengiz MUKU Gamze GUCLU Serkan SELLI*
}

\begin{abstract}
Özet
Bu çalışmada, ülkemizin Doğu Akdeniz bölgesinin Adana, Hatay ve Mersin illerinden temin edilen çiçek balı örneklerinin pestisit ve naftalin içeriklerinin belirlenmesi amaçlanmıştır. Bal örnekleri bölgedeki arıcı birliklerinden alınmıştır. Bal örneklerinde pestisit taraması, QuEChERS yöntemiyle ön işleme tabi tutulup, LC/MS/MS cihazıyla yapılmıştır. Analizler öncesi LC/MS/MS cihazıyla laboratuvarda, toplam 102 adet pestisit etken maddesi valide edilmiştir. Bal örneklerinin tamamında belirlenme sınırının (LOD) üstünde herhangi bir pestisite rastlanmamıştır. Naftalin analizi tepe boşluğu katı faz mikro ekstraksiyon (HS-SPME) GC/MS yöntemiyle yapılmıştır. Toplam 30 farklı bal örneğinin sadece bir tanesinde naftalin tespit edilmiştir. Naftalin değeri maksimum kalıntı değeri (MRL) seviyesi olan $10 \mathrm{ppb}$ nin altında bulunmuştur. İki bal örneğinde ise naftalin değeri LOD seviyesinin altında iz miktarda saptanmıştır. Bu sonuçlar 1şığında, ülkemiz Doğu Akdeniz bölgesi ballarının naftalin ve pestisit içermemesi hem tüketiciler ve hem de arıcılık sektörü açısından önemli bir bulgu olduğu düşünülmektedir.
\end{abstract}

Anahtar kelimeler: Bal, pestisit, naftalin, SPME, QuECheRS, LC/MS/MS

\section{Determination of Pesticide and Naphthalene Residues in Eastern Mediterranean Honey by LC/MS/MS and HS-SPME GC/MS}

\begin{abstract}
In this study, we aimed to determine the pesticide and naphthalene residues of 10 honey samples obtained from each of Adana, Hatay and Mersin provinces of Eastern Mediterranean region of Turkey. Honey samples were taken from the beekeeper units in the region. Pesticide screening in honey samples was pretreated by QuEChERS method and LC/MS/MS was performed. A total of 102 pesticide substances were validated in the laboratory by LC/MS/MS before the analyzes. No pesticide was detected in all honey samples above the detection limit (LOD). Naphthalene analysis was performed by headspace solid phase microextraction (HS-SPME) GC/MS. Naphthalene was detected in one sample of the 30 honey samples. This value remained below the maximum residue level (MRL) of $10 \mathrm{ppb}$. In the two honey samples, the value was lower than the LOD level. According to results, the fact that honey in our country's Eastern Mediterranean region does not contain naphthalene and pesticides, is considered to be an important finding for both consumers and the beekeeping sector.
\end{abstract}

Keywords: Honey, pesticide, naphthalene, SPME, QuECheRS, LC/MS/MS

ORCID ID (Yazar sirasina göre)

0000-0002-0370-7699, 0000-0001-7317-6101, 0000-0003-0450-2668

Yayın Kuruluna Geliş Tarihi: 14.11.2019

Kabul Tarihi: 17.12.2019

*Çukurova Üniversitesi, Ziraat Fakültesi, Gıda Mühendisliği Bölümü, Adana

E-mail: sselli@cu.edu.tr 


\section{Doğu Akdeniz Bölgesi Ballarının Pestisit ve Naftalin Kalıntılarının LC/MS/MS ve HS-SPME GC/MS ile Belirlenmesi}

\section{Giriş}

Türk Gıda Kodeksi 012/58 sayılı Bal Tebliği'nde, bal "bitki nektarlarının, bitkilerin canlı kısımlarının salgılarının veya bitkilerin canlı kısımları üzerinde yaşayan bitki emici böceklerin salgılarının, bal arısı 'Apis mellifera' tarafindan toplandiktan sonra kendine özgü maddelerle birleştirerek değişikliğe uğrattığı, su içeriğini düşürdüğü ve petekte depolayarak olgunlaştırdı $\breve{g}$ doğal olarak kristallanebilen doğal ürün" olarak tanımlamaktadır (Anonim, 2012). Kodeks Alimentarus (2001) ise balı "arıların topladığı bitki nektarlarını veya bitkilerin salgısını, kendine özgü spesifik maddelerle kombine ederek dönüştürdüğü, dehidre ettiği ve olgunlaşması içinde bal peteğine bıraktığı doğal tatlı madde" olarak tanımlamaktadır.

Türk Gıda Kodeksi'nde bal, kaynağına göre; bitkilerden toplanan nektarla üretilen çiçek balı ve bitki emici böceklerin salgılarından elde edilen salg1 balı olarak iki grupta siniflandirilmaktadir (Anonim, 2012). Salg1 balına örnek olarak çam balı verilebilir. Kızılçam ağacı üzerinde yaşayan çam koşnili, ağaçtan emdiği özsudaki proteini kendi bünyesine alıp, geri kalanı şekerli bir salg1 olarak dışarı verir. $\mathrm{Bu}$ salgı, bal arılarınca toplanarak çam balı haline getirilmektedir. Dünyadaki çam balının neredeyse tamamı ülkemizde üretilmekte olup, aroması ve zengin içeriğiyle büyük talep görmektedir. Çiçek balları ise, arıların nektarlarını topladıkları kaynağın ismini alırlar; buna örnek olarak kestane, narenciye ve kekik balı verilebilir (Öztürk, 2001).

Türlerine göre değişmekle beraber, balın yaklaşık \%18'i su ve \%77'si şekerdir. Geri kalan \%5'lik kısım ise organik asitler, proteinler (albümin, globülin), vitaminler, mineraller ( $\mathrm{K}, \mathrm{P}, \mathrm{Mg}, \mathrm{Ca}$ ) ve enzimler (glukoz oksidaz, amilaz, invertaz)'den oluşmaktadır (Blasko ve ark., 2011). Bu içeriği balı, sindirimi kolay, enerji verici, hastalıkları önleyici ve tedavi edici yapar. Tüm bu özelliklerinden dolayı ballar fonksiyonel gıdalar içerisinde değerlendirilmektedir (Chepulis, 2007; (Kujawski ve Namiesnik, 2011).
Tarımsal uygulamalar doğada kalıntılara neden olur ve bu kalıntıların miktarı ve zehir düzeyi, çoğu zaman doğanın kendi kendini temizleme dengesini aşmaktadır (Barganska ve ark. 2013). Bal ve arı ürünlerinin doğal, sağlıklı ve kirleticilerden temiz bir imaj1 vardır. Buna rağmen üretildiği yerlerin çoğu maalesef kirlenmiş çevredir. Günümüzde kirleticilerden en önemlisi olarak pestisitler karşımıza çıkmaktadır. Pestisitlerin, çevreye direnci ve yaygın kullanımı yüzünden bala da bulaşma olasılığ 1 yüksektir. Arıcılık faaliyetlerinden doğrudan bulaşmanın yanı sıra, çevresel kaynaklardan dolaylı olarak da bulaşılar olabilmektedir. Pestisit kalıntılarının genetik mutasyona ve hücresel bozulmaya ilaveten çeşitli toplumsal sağlık problemlerine yol açabildiği bildirilmiştir (Shendy ve ark 2016). Pestisit kullanımının fazla olması ise zararlı kontrolü, verimliliğin artırılması ve masrafların azaltılması amaçlarından kaynaklanmaktadır. Ancak pestisitlerin sürekli ve yanlış kullanımı su, toprak, hava ve bitkilerin kirlenmesine neden olmakta, daha da ileri giderek yararlı böceklerin (arılar) yok olmasına, yeni zararlıların ortaya çıkmasına ve zararlı popülasyonunun direnç kazanmasına neden olmaktadır (Oliviera ve ark. 2016).

En az pestisitler kadar tehlikeli diğer kirletici de polisiklik aromatik hidrokarbonlardır $(\mathrm{PAH})$ Mutajenik ve kanserojenik özelliklerinden dolayı Avrupa Birliği tarafindan öncelikli kirletici madde olarak karakterize edilmiştir. PAH'lar bitmemiş yanma reaksiyonları, organik materyalin 1 s1 bozunması, endüstriyel işlemler ve diğer insan aktiviteleriyle oluşan önemli çevresel kirleticidir. Naftalin ve türevleri, sıklıkla belirlenen PAH bileşiklerindendir. Naftalin arıcılar tarafından mum güvesini uzaklaştırıcı olarak kullanılmaktadır. Bal peteğinin depolanması sırasında kullanılan naftalin, bala ve polene geçebilmektedir (Koltsakidou ve ark., 2015). Yüksek miktarlarda naftaline maruz kalındığında hemolitik anemi yani kırmızı kan hücreleri yıkımı görülebilmektedir (Beyoğlu, 2006).

Pestisitlerin ve naftalinin insan sağlığı üzerinde birçok olumsuz etkileri vardır. Aynı 


\section{Doğu Akdeniz Bölgesi Ballarının Pestisit ve Naftalin Kalıntılarının LC/MS/MS ve HS-SPME GC/MS Teknikleriyle Belirlenmesi}

zamanda bu kirleticiler balın ekonomik değerini düşürmekte ve ihracat yolunu kapatmaktadır. Öte yandan, son yillarda bal arısı ve bal ürünleri çevresel kirlenmenin biyobelirteci olarak kullanılmaya başlanmıştır. Bu çalı̧̧mada, Doğu Akdeniz bölgesindeki üç farklı lokasyondan (Mersin, Adana ve Hatay) 2016 yılında arıcı birlikleri ve piyasadan toplanan bal örneklerinde pestisit ve naftalin kalıntılarının belirlenmeleri amaçlanmıştır. Bal örneklerinde pestisit analizi için QuEChERS (Quick-Easy-CheapEfficient-Rugged-Safe) yöntemiyle siv1 kromatografi- tandem kütle spektrometresi (LC/MS/MS) cihazı kullanılmıştır. Naftalin analizi için ise Tepe boşluğu-Katı faz mikro ekstraksiyon (HS-SPME) metodu uygulanıp gaz kromatografisi -kütle spektrometresi (GC/MS) kullanılmıştır.

\section{Materyal ve Yöntem \\ Materyal}

$\mathrm{Bu}$ çalışmada Doğu Akdeniz bölgesine ait 2016 yılı çiçek balları kullanılmıştır. Doğu Akdeniz bölgesini temsilen Adana (A1-10), Hatay (H1-10) ve Mersin (M1-10) illeri aric1 birliklerinden temin edilen 10'ar adet, toplamda 30 adet bal toplanmıştır. Her bir bal örneğinden yaklaşık $500 \mathrm{~g}$ örnek alınmıştır. Toplanan örnekler hermetik kapatılmış kavanozlarda, analizler başlayıncaya kadar 18 C'de saklanmıştır.

\section{Yöntem}

\section{Ballarda pestisit analizi}

Bal örneklerinin pestisit analizinde QuEChERS (Quick Easy Cheap Efficient Rugged Safe) yöntemi olarak bilinen AOAC 2007.01 metodu (Lehotay, 2007) uygulanmıș ve API3200 marka LC/MS/MS (AB SCIEX, Framingham, ABD) cihazı kullanılmıştır. Bu yöntem bal örneklerinde pestisit analizleri için önceki çalışmalarda oldukça yoğun kullanılmıştır (Flores ve ark., 2017; Barganska ve ark., 2018).

Bu yöntemde, $5 \mathrm{~g}$ bal örneği, $15 \mathrm{ml}$ asetonitril (\%1 asetik asit), $6 \mathrm{~g}$ magnezyum sülfat ve 1.5 g sodyum asetat ile karıştırılmış ve karışım santrifüj edilmiştir. Üst fazdan $8 \mathrm{ml}$ alınarak, $1200 \mathrm{mg}$ magnezyum sülfat, $400 \mathrm{mg} \mathrm{C} 18,400$ mg primer sekonder amin (PSA) ile vorteks yapılarak karıştırılmış ve karışım tekrar santrifüj edilmiştir. Üst fazdan $1 \mathrm{ml}$ alınarak LC/MS/MS'e enjekte edilmiştir. Örnekler 3 tekerrürlü çalışılmıştır. Kalibrasyon grafiği 5 , $10,20,50$ ve $100 \mathrm{ppb}$ konsantrasyonlarında bal örneği ile matris eşleştirme yöntemi kullanılarak hazırlanmıştır. LC-MS/MS çalışma koşulları Çizelge 1'de verilmiştir.

Çizelge 1. LC-MS/MS çalışma koşulları

\begin{tabular}{|c|c|}
\hline Kolon sicaklı ̆̆ & $50^{\circ} \mathrm{C}$ \\
\hline Ak1ş H1z1 & $0,25 \mathrm{ml} / \mathrm{dk}$ \\
\hline Enjeksiyon miktarı & $10 \mu 1$ \\
\hline Kolon & $\begin{array}{l}\text { Synergy 4u Fusion- } \\
\text { RP 80A }\end{array}$ \\
\hline Çalıșma süresi & $20 \mathrm{dk}$ \\
\hline \multirow[t]{2}{*}{ Mobil Faz } & $\begin{array}{l}\text { A: Metanol }+50 \mathrm{mM} \\
\text { Amonyum Format }\end{array}$ \\
\hline & $\begin{array}{l}\mathrm{B}: \mathrm{Su}+50 \mathrm{mM} \\
\text { Amonyum Format }\end{array}$ \\
\hline $\begin{array}{l}\text { İyon } \\
\text { sicaklığg }\end{array}$ & $130^{\circ} \mathrm{C}$ \\
\hline
\end{tabular}

\section{Ballarda naftalin analizi}

Bal örneklerinin naftalin analizinde son yıllarda yoğun bir şekilde kullanılan HSSPME (Tepe Boşluğu- Katı Faz Mikro Ekstraksiyon) metodu uygulanmış ve GC/MS cihazında analiz edilmiştir. Cihaz olarak Agilent 6890N-5975B kütle dedektörü ve Agilent GC Sampler80 kullanılmıştır.

Analizler öncesi kullanılan fiber ekstraksiyon öncesi temizlik amaciyla GC-MS'te desorbe edilerek temizlenmiştir. Daha sonra $1 \mathrm{~g}$ bal örneği alınmış ve $10 \mathrm{ml}$ saf suyla seyreltilmiştir. Naftalin analizlerinde SPME yöntemi için polidimetilsiloksan (PDMS) fiberi kullanılmıștır. SPME analizinde bal örnekleri $40^{\prime} \mathrm{C}^{\prime} \mathrm{de} 30 \mathrm{dk}$ süreyle otomatik sistemde karıştırılmış ve naftalinlerin PDMS fibere tutunması sağlanmıştır. Daha sonra fiber alınarak GC-MS'e desorbe edilerek analiz tamamlanmıştır. GC/MS cihazı çalışma koşulları Çizelge 2.' de verilmiştir. Her bir örnek 3 tekerrürlü olarak çalış1lmıştır.

Çizelge 1. GC/MS cihazı çalışma koşulları

\begin{tabular}{|l|l|}
\hline Enjektör sıcaklığ 1 & $220^{\circ} \mathrm{C}$ \\
\hline \multirow{2}{*}{$\begin{array}{l}\text { Firın çalışma } \\
\text { programı }\end{array}$} & $40^{\circ} \mathrm{C}-5 \mathrm{dk}$ \\
\cline { 2 - 2 } & $55^{\circ} \mathrm{C}-1{ }^{\circ} \mathrm{C} / \mathrm{dk}$ \\
\cline { 2 - 2 } & $120^{\circ} \mathrm{C}-10^{\circ} \mathrm{C} / \mathrm{dk}$ \\
\hline
\end{tabular}




\section{Doğu Akdeniz Bölgesi Ballarının Pestisit ve Naftalin Kalıntılarının LC/MS/MS ve HS-SPME GC/MS ile Belirlenmesi}

\begin{tabular}{|l|l|}
\hline & $220^{\circ} \mathrm{C}-220^{\circ} \mathrm{C} / \mathrm{dk}$ \\
\hline He gazı akış hızı & $1 \mathrm{ml} / \mathrm{dk}$ \\
\hline Girişim sıcaklığ 1 & $280^{\circ} \mathrm{C}$ \\
\hline $\begin{array}{l}\text { Iyon kaynağ } \\
\text { sicaklı̆̆ } 1\end{array}$ & $230^{\circ} \mathrm{C}$ \\
\hline Kuadrupol sıcaklığ 1 & $150^{\circ} \mathrm{C}$ \\
\hline
\end{tabular}

\section{Bulgular ve Tartışma \\ Balların Pestisit İçeriği}

Bal örneklerinin analizleri öncesi SANTE/11228/2017 (Avrupa Komisyonu Gıda ve Sağlık Müdürlüğü) belgesindeki direktifler uygulanarak metodumuz analizler öncesi hassas şekilde valide edilmiştir. Bu belgedeki metot performans kriterleri geri kazanım için \% 70-120 ve tekrarlanabilirlik ve tekrar üretilebilirlik için \%RSD (Bağıl standart sapma $<20$ olarak bildirilmiştir. Çalı̧̧mamızda, pestisit içermeyen bal numunesinde 50 ppb konsantrasyonda olacak şekilde 5 adet geri kazanım çalışması yapılmıştır. Bal örneğinde tekrarlanabilirlik için $50 \mathrm{ppb}$ konsantrasyonda 10 adet çalışma yapılmıştır. Tekrar üretilebilirlik için ise iki farklı personel tarafindan 50 ppb konsantrasyonda çalışma yapılmıştır. Günde 2 'şer defa olmak üzere 3 farklı günde toplamda 6 adet çalışma yapılmıştır.

Pestisit tespiti için 5, 10, 20, 40, 60, 80 ve 100 ppb etken madde içeren çözeltiler asetonitril içerisinde 3 paralelli olarak hazırlanmış ve kalibrasyon grafiği oluşturulmuştur. Kalibrasyon sonucunda elde edilen bulgular tespit limitlerinin (LOD) hesaplanmasinda kullanılmıştır. LOD değeri, bir örnekte herhangi bir analitin, belirlenebildiği en düşük konsantrasyonu ifade etmektedir.

Analizler öncesi 102 adet pestisitin her biri için validasyon çalışması yapılmıştır. Validasyon çalışmaları sonucunda \% geri kazanım ortalaması \% 98.4, tekrarlanabilirlik $\%$ RSD değeri \%6.3 ve tekrar üretilebilirlik \% RSD değeri 11.1 olarak hesaplanmıştır. Metot, pestisit analizleri için valide edildikten sonra, 30 bal örneği QuEChERS yöntemiyle eksrakte edilip sırasıyla LC/MS/MS'e enjekte edilmiştir. Elde edilen verilere göre Doğu Akdeniz bölgesinden temin ettiğimiz 30 bal örneğinin hiçbirinde belirlenme seviyesinin
(LOD seviyesi) üstünde bir pestisit kalıntıs1 bulunmamıştır. $\mathrm{Bu}$ bulgular 1şığında, ülkemizde bal üretimi yapan üreticilerin, Tarım İl Müdürlükleri ve Arıcı Birlikleri tarafından özellikle pestisit konusunda bilgilendirmeleri ile sağliklı üretim bilincinin oluştuğu söylenebilmektedir.

Benzer şekilde, Çin'de Zhang ve ark. (2011) dispersif siv1-siv1 mikroekstraksiyon metodunu bal örneklerinde piretiroid grubu pestisitler için valide edip, HPLC-DAD ile kombine kullanmışlardır. Araştırma sonucunda, bal örneklerinde piretiroid grubu pestisitlere rastlanmadığı belirtilmiştir. Yine 2011 yılında, Kujawski ve Namiesnik tarafından Polonya'da yapılan çalışmada, 40 bal örneğinde 13 farklı pestisit etken maddesi araştırılmıştır. Araştırmacılar, balda bulunan pestisit kalıntılarının bizim çalışmada olduğu gibi LOD seviyesinin altında olduğunu belirtmişlerdir. 2012 yılinda ise Zacharis ve ark. (2012) Yunanistan'ın 15 farklı bal örneklerinde organik klorlu pestisit etken maddeleri araştırmış ve çalışma sonucunda örneklerin hiçbirinde organik klorlu pestisit etken maddelerine rastlanılmadığ bildirilmiştir.

\section{Balların Naftalin İçeriği}

Naftalin kolayca buharlaşan, güçlü fakat kötü kokulu, yanıcı, beyaz katı bir maddedir. Petrol ve kömür gibi fosil yakıtların doğal bileşenidir. Endüstride birçok alanda; reçineler, fitaleinler, boyalar, eczacillk ürünleri, böcek öldürücüler, diğer materyallerin üretiminde ve güveye karş1 püskürtülerek kullanılmaktadır (Dobrinas vd. 2008, Lambert vd. 2012). Naftalin, sonbaharda bal süzüldükten sonra uygun biçimde depolanmayan peteklerde mum güvesine karşı kullanılmaktadır. Petekler koloniye tekrar verilirken içerdikleri naftalin de tekrar bala geçmektedir. Vücuda girdiği zaman az oranda kanda çözülmekte, yüksek miktarlarda naftaline maruz kalındığında kırmızı kan hücrelerinde zarar ve yıkıma neden olabilmektedir. Bu durum hemolitik anemi olarak adlandırılmaktadır (Beyoğlu, 2006). Ülkemizde Türk Gıda Kodeksi, balda bulunabilecek naftalin miktarının üst limitini $10 \mathrm{ppb}$ olarak belirlemiştir (Anonim, 2012). 


\section{Doğu Akdeniz Bölgesi Ballarının Pestisit ve Naftalin Kalıntılarının LC/MS/MS ve HS-SPME GC/MS Teknikleriyle Belirlenmesi}

Ülkemiz Doğu Akdeniz illerinden alınan 30 farklı çiçek balında naftalin varlığı, tepe boşluğu katı faz mikroekstraksiyon (HSSPME) yöntemiyle GC-MS sisteminde analiz edilmiştir. Elde edilen bulgular Çizelge 3'te verilmiştir. Ballarda analizler öncesi GCMS'e naftalin saf standardı enjekte edilmiş ve bu şekilde hem tanımlamanın güvenilirliği arttırılmış ve hem de miktar tayininde hassas çalışıllmıştır. Naftalin standardının GC-MS kromatogramı Şekil 1.'de verilmiştir. Şekil 1 'de görüldüğü gibi naftalin GC-MS kromatogramında yaklaşı 9.84 dakika'da çıkmaktadır.

Çizelge 5'te verilen örneklerin naftalin analiz sonuçlarına gelince, bal örneklerinden 27'sinde naftalin saptanmazken, sadece birinde (A-5) 8,76 ppb düzeyinde naftalin belirlenmiş ve 2 adet numunede ise LOD değerinin altında yani oldukça iz miktarda naftalin tespit edilmiştir. Şekil 2.'de naftalinin $\mathrm{m} / \mathrm{z}$ iyonlar1 128 (temel pik), 102 ve 136 ile A5 bal örneğinde tespit edilen naftalinin kromatogramı görülmektedir.

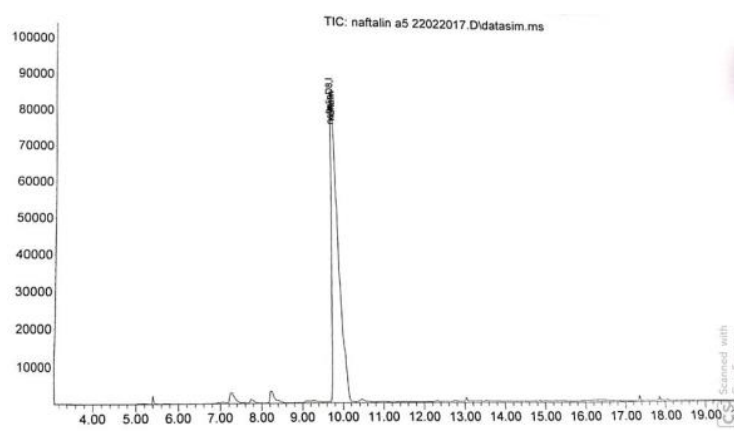

Şekil 1. Miktar tayini için kullanılan naftalin standardının GC-MS kromatogramı

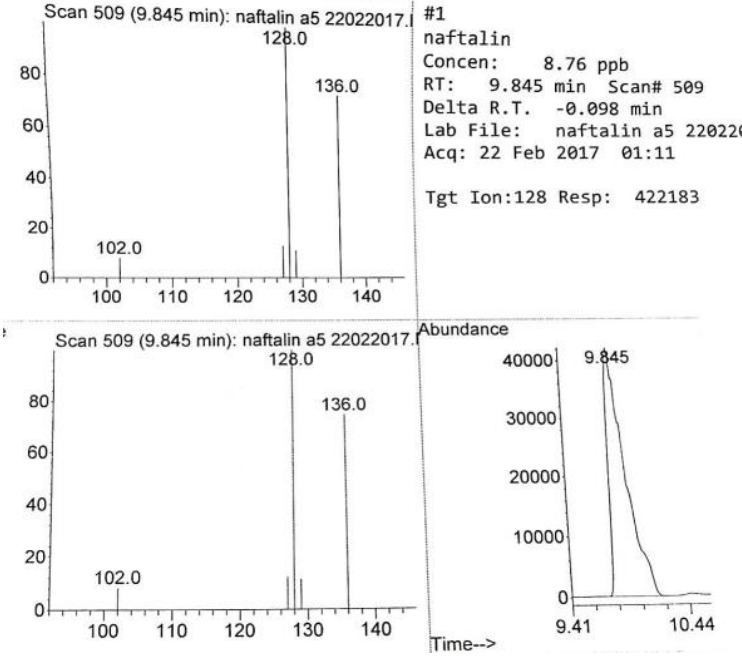

Şekil 1. A-5 bal örneğinde tespit edilen naftalinin GC-MS spektrumu ve kromatogram 1

Analiz sonuçlarına göre Doğu Akdeniz bölgesi ballarımız naftalin açısından bir örnek hariç oldukça temiz bulunmuştur. Balda arıcılar tarafından mum güvesini uzaklaştırıcı olarak kullanılan naftalin bal peteğinin depolanması sırasında bala ve polene geçebilir ve tüketici sağlığını olumsuz etkileyebilir. Ülkemizdeki düzenlemeler incelendiğinde Türk Gıda Kodeksi Bal Tebliği'nde (Anonim, 2012) atıf yapılan Türk Gıda Kodeksi Hayvansal Gidalarda Bulunabilecek Farmakolojik Aktif Maddelerin Sinıflandırılmas1 ve Maksimum Kalıntı Limitleri Yönetmeliği balda naftalin için MRL limiti 10 ppb olarak belirlemiştir.

Çizelge 3. Ballarda naftalin analiz sonuçları

\begin{tabular}{|l|l|}
\hline $\begin{array}{l}\text { Numune } \\
\text { Adı }\end{array}$ & Naftalin Değeri \\
\hline A1 & iz \\
\hline A2 & T.E.D.B. \\
\hline A3 & iz \\
\hline A4 & T.E.D.B. \\
\hline A5 & $8,76 \mathrm{ppb}$ \\
\hline A6 & T.E.D.B. \\
\hline A7 & T.E.D.B. \\
\hline A8 & T.E.D.B. \\
\hline A9 & T.E.D.B. \\
\hline A10 & T.E.D.B. \\
\hline H1 & T.E.D.B. \\
\hline H2 & T.E.D.B. \\
\hline
\end{tabular}




\begin{tabular}{|l|l|}
\hline H3 & T.E.D.B. \\
\hline H4 & T.E.D.B. \\
\hline H5 & T.E.D.B. \\
\hline H6 & T.E.D.B. \\
\hline H7 & T.E.D.B. \\
\hline H8 & T.E.D.B. \\
\hline H9 & T.E.D.B. \\
\hline H10 & T.E.D.B. \\
\hline M1 & T.E.D.B. \\
\hline M2 & T.E.D.B. \\
\hline M3 & T.E.D.B. \\
\hline M4 & T.E.D.B. \\
\hline M5 & T.E.D.B. \\
\hline M6 & T.E.D.B. \\
\hline M7 & T.E.D.B. \\
\hline M8 & T.E.D.B. \\
\hline M9 & T.E.D.B. \\
\hline M10 & T.E.D.B. \\
\hline
\end{tabular}

*T.E.D.B.: Tespit edilebilir düzeyde bulunamadı.

Görüldüğg̈ üzere, A-5 örneğinde belirlenen naftalin miktarı, yönetmelikte belirtilen sınıra oldukça yakın olmasına rağmen, bu değerin altında bulunmuştur. Naftalin arıcılık sektörü için yıllarca çok önemli sorun olmuştur ve özellikle bal ihracatında ülkemiz için en büyük engeli teşkil etmiştir. Çalışmamız sonucunda ise, bu konuda ülkemizde bal üreticilerine verilen eğitimlerin naftalin konusunda bilinç oluşturduğu ve eğitimlerin Doğu Akdeniz Bölgesi balları için olumlu sonuç vermeye başladığı görülmektedir.

Benzer şekilde, Castle ve ark. (2004) İngiltere'de bal örneklerinde naftalin taramas1 yapmışlardır. Marketlerden alınan 49 adet bal örneğinde yaptıkları bu çalışmada, örneklerin hiçbirinde naftaline rastlanmadığı bildirilmiştir. Ülkemizde, Beyoğlu ve ark. (2007) tarafindan ballarda naftalin aranmasi konusunda bir çalışma yapılmıştır. Araştırmacılar, marketlerde ve halk

\section{Kaynaklar}

Anonim 2012, Tük Gıda Kodeksi, Bal Tebliği (2012/58). Başbakanlık Basımevi, Ankara.

Barganska, Z., Konieczka, P., Namiesnik, J., 2018. Comparision of two methods for the determination of selected pesticides in honey and honeybee samples. Molecules, 23:2582. pazarlarında satılan 100 adet baldan, sadece birinde $1,13 \mathrm{ppb}$ oranında naftalin bulmuşlardır. Öte yandan, Tsimeli ve ark. (2008), balda naftalin tespiti için metot araştırmışlardır. GC-SPME metodunu optimize ederek, tuz ilavesi, ekstraksiyon sicaklığ 1 ve süresinin metodun başarısı için önemli olduğunu ifade etmişlerdir. Araştırmacılar, çalışma sonucunda bal örneklerinde naftalin bulunmadığını bildirmişlerdir.

\section{Sonuç}

$\mathrm{Bu}$ çalışmada, Adana, Mersin ve Hatay illerindeki arıcı birliklerinden temin edilen 30 farklı çiçek balının pestisit ve naftalin yönünden incelenmesi gerçekleştirilmiştir. Analiz edilen bal örneklerinin tamamında belirlenme sınırının (LOD) üstünde bir pestisite rastlanmamıştır. Naftalin analizi sonucunda ise toplam 30 bal örneği içerisinde sadece bir tanesinde naftalin tespit edilmiştir. $\mathrm{Bu}$ değer maksimum kalıntı seviyesi olan 10 ppb'nin altında kalmıştır. İki bal örneğinde ise naftalin değeri LOD seviyesinin altında çıkmıştır. Çalışmamızın sonucunda, Doğu Akdeniz ballarında pestisit ve naftalin bulunmaması bal üretici ve tüketicileri için önemli bir bulgu olmuştur. $\mathrm{Bu}$ bulgular 1şı̆̆ında, ülkemizde bal üreticileri bilgilendirmek amaciyla verilen eğitimlerin bir bilinç oluşturduğu ve üretimi olumlu yönde etkilediği görülebilmektedir.

\section{Teşekkür}

$\mathrm{Bu}$ araştırmayı maddi olarak destekleyen Çukurova Üniversitesi Bilimsel Araştırma Proje Koordinatörlüğüne (Proje No: FYL2016-6706) teşekkürlerimizi sunarız.

Barganska, Z., Slebioda, M., Namiesnik, J., 2013. Pesticide residues levels in honeys from apiaries located of Northern Poland. Food Control, 31:196201.

Beyoglu, D. 2006, Türkiye'nin çeşitli bölgelerinde temin edilen bal örneklerinden naftalin aranması ve miktar tayini. Marmara Üniversitesi Yüksek Lisans Tezi.

Beyoglu, D., Omurtag, G., 2007, ocuurence of naphthalene in honey consumed in 


\section{Doğu Akdeniz Bölgesi Ballarının Pestisit ve Naftalin Kalıntılarının LC/MS/MS ve HS-SPME GC/MS Teknikleriyle Belirlenmesi}

Turkey as determined by high pressure liquid chromatography. Journal of Food Protection, 70:1735-1738.

Blasco, C., Vazquez, P., Onghena, M., Masia, A., Pico, Y., 2011, Analysis of insectisides in honey by liquid chromatography ion trap mass spectrometry: Comparison of different extraction procedures. Journal of Chromatography A, 1218:4892-4901.

Castle, L., Philo, M., Sharman, M., 2004. The analysis of honey samples for residues of nitrobenzene and petroleum from the possible use of Frow mixture in hives. Food Chemistry, 84:643-649.

Chepulis, L. M. 2007, The effect of honey compared to sucrose, mixed sugars, and a sugar-free diet on weight gain in young rats. Journal of Food Science, 72(3), S224-S229.

Dobrinas, S., Birghila, S., Coatu, V., 2008. Assesment of polycyclic aromatic hydrocarbons in honey and propolis produced from varius flowering trees and plants in Romania. Journal of Food Composition and Analysis, 21:7177.

Flores, C., Rsales, V., ramirez, O., Loza, L., Ugalde, J., 2017. Agricultural pesticide residues in honey and wax combs from southeastern, central and northeastern Mexico. Journal of Apicultural Research, 56:667-679.

Kodeks Alimentarius, 2001. Revised Codex Standard for Honey, Codex STAN 121981, Rev. 1 (1987), Rev. 2.

Koltsakidou, A., Zacharis, C. K., Fytianos, K. 2015, A validated liquid chromatographic method for the determination of polycyclic aromatic hydrocarbons in honey after homogeneous liquid-liquid extraction using hydrophilic acetonitrile and sodium chloride as mass separating agent. Journal of Chromatography A, 1377, 4654.

Kujawski, M., Namiesnik, J., 2011. Levels of 13 multiclass pesticide residues in Polish honeys determined by LC-ESI-MS/MS. Food Control, 22:914-919.

Lambert, O., Veyrand, B., Durand, S., Marchand, P., Le Bizec, B., Piroux, M., Pouliquen, H. 2012, Polycyclic aromatic hydrocarbons: bees, honey and pollen as sentinels for environmental chemical contaminants. Chemosphere, 86(1), 98104.

Lehotay, S. 2007, AOAC official method 2007.01 pesticide residues in foods by acetonitrile extraction and partitioning with Magnesium Sulfate. Journal of AOAC International, 90(2), 485-520.

Oliviera, R., Queiroz, S., Luz, C., Prto, R., Rath, S., 2016. Bee polen as a bioindicator of environmental pesticide contamination. Chemosphere, 163:52553.

Öztürk, A.Ğ. 2001. Arıcılık, Tarım ve Köyişleri Bakanlığı, Teşkilatlanma ve Destekleme Genel Müdürlüğü, Ankara.

Shendy, A., Ghobashy, M., Mhammed, M., Alla, S., Ltfy, H., 2016. Simultaneous determination of 200 pesticide residues in honey using gas chromatgraphy tandem mass spectrometry in conjuction with stream lined quantification approach. Journal of Chromatography A, 1427:143-160.

Tsimeli, K., Triantis, T., Dimotikali, D., 2008. Development of a rapid and sensitive method for the simultaneous determination of 1,2-dibromoethane, 1,4dichlorobenzene and naphthalene residues in honey using HS-SPME coupled with GC-MS. Analytica Chimica Acta, 617:64-71.

Zacharis, C., Rotsias, I., Zachariadis, P., Zotos, A., 2012. Dispersive liquid-liquid microextraction for the determination of organochlorine pesticides residues in honey by gas chromatography-electron capture and ion trap mass spectrometric detection. Food Chemistry, 134:16651672.

Zhang, J., Gao, H., Peng, B., Li, S., Zhou, Z., 2011. Comparision of the performance of conventional, temperature-controlled, and ultrasound assisted ionic liquid dispersive liquid-liquid microextractrion combined with high performance liquid chromatography in analyzing pyrethroid pesticides in honey samples. Journal of Chromatography A, 1218:66216629. 